\title{
Referrals to Emergency Departments- The Processes and Factors That Influence Decision-Making among Community Nurses
}

\author{
Annica Kihlgren ${ }^{1}$, Helena Sunvisson ${ }^{1}$, Kristina Ziegert ${ }^{2}$, Anna-Greta Mamhidir ${ }^{3,4}$ \\ ${ }^{1}$ School of Health and Medical Sciences, Örebro University, Örebro, Sweden \\ ${ }^{2}$ School of Social and Health Sciences, Halmstad University, Halmstad, Sweden \\ ${ }^{3}$ Department of Health and Caring Sciences, Faculty of Health and Occupational Studies, University of Gävle, Gävle, \\ Sweden \\ ${ }^{4}$ Department of Public Health and Caring Sciences, Uppsala University, Uppsala, Sweden \\ Email: *annica.kihlgren@oru.se
}

Received 17 December 2013; revised 24 March 2014; accepted 7 April 2014

Copyright (C) 2014 by authors and Scientific Research Publishing Inc.

This work is licensed under the Creative Commons Attribution International License (CC BY).

http://creativecommons.org/licenses/by/4.0/

(c) (1) Open Access

\section{Abstract}

The aim of the study was to describe the basis on which municipal care registered nurses (RN) make decisions and their experiences when referring older persons from nursing homes to emergency departments (EDs). RNs in the community are to ensure that older adults receive good care quality in nursing home. This study used a descriptive design with a qualitative content analysis. The analysis of the data from the 13 interviews revealed one theme "Shared responsibilities in the best interests of the older person reduce feelings of insufficiency". The content was formulated, which revealed the RNs' feelings, reasoning and factors influencing them and their actions in the decision-making situation, before the patients were referred to an emergency department. Complex illnesses, non-adapted organizations, considerations about what was good and right in order to meet the older person's needs, taking account of her/his life-world, health, well-being and best interests were reported. Co-worker competencies and open dialogues in the "inner circle" were crucial for the nurses' confidence in the decision. Hesitation to refer was associated with previous negative reactions from ED professionals. The RN sometimes express that they lacked medical knowledge and were uncertain how to judge the acute illness or changes. Access to the "outer circle", i.e. physicians and hospital colleagues, was necessary to counteract feelings of insecurity about referrals. When difficult decisions have to be made, not only medical facts but also relationships are of importance. To strengthen the RNs' and staff members' competence by means of education seems to be important for avoiding unnecessary referrals. Guidelines and work routine need to be more transparent and referrals due to the lack of resources are not only wasteful but can worsen the older persons' health.

\footnotetext{
*Corresponding author.
}

How to cite this paper: Kihlgren, A., Sunvisson, H., Ziegert, K. and Mamhidir, A.-G. (2014) Referrals to Emergency Departments-The Processes and Factors That Influence Decision-Making among Community Nurses. Open Journal of Nursing, 4, 366-374. http://dx.doi.org/10.4236/ojn.2014.45042 


\section{Keywords}

\section{Emergency Department, Older Persons, Municipal Care, Registered Nurse, Decision Making}

\section{Introduction}

Decision making is regarded as an essential component of the nursing role and can be defined as a process used by nurses to gather information about patients, evaluate it, and make judgments that result in the provision of nursing care [1]. Nursing judgments are complex and often involve the need to process a large number of informational cues. Knowledge and clinical experience are the most important factors in clinical decision making [2]. There is a need to develop the body of knowledge about how to implement evidence-based practice in decision making on micro- and macro-levels in community nursing care [3].

This study focuses on registered nurses' (RNs) decision making in the community when older persons' health status deteriorates and decisions about referrals from nursing homes to an emergency department (ED) have to be taken. It has been suggested that based on the older person's actual physical condition and need for ED services, up to $50 \%$ of ED referrals from nursing homes are unwarranted [4]-[6]. There is a need for more research about events pertinent to decision making behind nursing homes' referrals to the ED, such as the context and decision-makers' considerations, in order to understand more about how such decisions are taken [7]. Less than two thirds of the older persons who arrive from nursing homes or leave an ED have complete nursing documentation [6].

In a recent study, McCloskey [8] described three nursing home situations that led to referrals, and he found that the RNs were the main decision makers and initiated all referrals-a routine procedure according to the policy of the nursing homes in question. A study of decision making, before referrals from nursing homes to EDs, revealed that the ideal situation occurred when consensus was reached about the severity and acuity of the problems by the different parties involved, usually licensed practical nurses, family members, physicians, and the older person. Conflicts arose if there were disagreements between two or more of those involved in the referral decision [7].

Complexity is considered present in decision making, for example, when a decision has to be made about whether or not a patient with a deteriorated health status should be referred to an ED. This includes identifying the patient's problems, assessing resources, and the patient's autonomy. "Knowing the patient" is an important concept in nursing [9] and an essential prerequisite when planning and providing high quality care [10] [11]. It is critical for RNs to have good self-esteem due to the solitary nature of the work as well as an ability to work autonomously [12].

RNs are responsible for the quality of nursing care, have to ensure that the older persons receive proper care, and supervise other staff members [13]. During normal day shifts, RNs can be responsible for one or more nursing home wards. On evening, night and holiday shifts, an RN can be responsible for residents in several NHs as well as for older persons living in their own homes within the catchment area. They regularly take decisions about referrals from NHs to EDs. During the day the nurses can consult the physician on call at a Primary Health Care Centre; outside normal daytime hours they can consult a physician on call through a SOS-alarm [14].

Various factors that can influence the RNs referral decisions have been described. For example, due to the low number of emergency beds, nurses endeavored to make a correct decision, but often lacked confidence in their ability to assess the patient's health status [15]. Nurses are required to work according to the best evidence-based practice, which includes a decision-making process encompassing the concerns and values of the patient, the practitioner's experience, and common sense, in addition to the best available research evidence. Netting and O'Connor [16] reported that being able to assess the situation and recognize the context in which one is making decisions sets, the stage for how evidence-based practice is defined and used. Nyström et al. [17] stressed that the human perspective must be taken into account, as unnecessary referrals of frail older persons can lead to deterioration in their condition, decrease their well-being, and cause confusion.

\subsection{Literature Review}

In a literature review, McCloskey and Hoonaard [18] reported that knowledge about referrals to EDs of persons 
living in nursing homes has mainly been based on retrospective record reviews, while the events that led to the referrals were sparsely examined. Recently, McCloskey [8] investigated older persons' entire referral situation from a nursing home to an ED and highlighted its complexity. Lack of communication between the parties was found, as was the older persons' frustrations when they felt that their health concerns were not taken seriously. For their part, the caregivers stated that their decisions and the care they provided were a result of the environment in which they worked. The results of the study from Finland showed important implications for the home care of older home care clients. First, home care services need to provide a service that meets the clients' specific needs, and these must be taken into account at an organizational level. Second, home care professionals need more continuing education and the skills to recognize and to use the many different potential resources that each client is able to access, which could enhance their daily living [19]. A qualitative study from Norway explored patient safety and falls, based on the experiences of home care nurses. In summary, the findings showed that home care nurses felt that healthcare personnel were more concerned with the treatment of falls, rather than fall prevention. The nurses described the helplessness they felt for those vulnerable patients living at home, currently waiting for a place in a nursing home [20].

There is a need for increased knowledge of the processes and factors that influence decisions about nursing home referrals to EDs and to more closely explore the RNs’ decision-making process.

\subsection{Aim}

The aim of the study was to describe the basis on which RNs make decisions, when referring to older persons from nursing homes to emergency departments (ED).

\section{Method}

\subsection{Design}

This is part of a longitudinal, follow-up study that examined older persons' disabilities, resources and needs in one county, comprising ten communities in a rural area of south-north Sweden. The ten communities served approximately 270,000 inhabitants, of which 24 nursing homes where every referral and reason for the referral of an older person to an ED was reported and analysed over a one-year period [21]. For every tenth transfer, the patient, her/his relatives, the physician, and the RNs involved were asked to participate in an interview concerning their experience of the circumstances surrounding the referral. The present study analyses the interviews conducted with 13 RNs that accepted to participate in the study, working at 11 of the 24 nursing homes, and who had four to eighteen years of eldercare work experience.

\subsection{Data Collection}

All patient ED referrals were documented in medical records. The referring nurses copied their ED referrals' documentation and faxed it to a research unit. The documentation was coded and the information checked by a research assistant. Every 13 RNs were contacted and invited to take part in an interview. An appointment was made with those who accepted. To acquire a deeper understanding of what might influence nurses' decision making, such as factors contributing to their hesitation about a referral, they were encouraged to talk openly about their experience of situations where the older person's health had deteriorated and they had decided to make a referral. Follow-up questions were: "Please tell me more about that" and "What do you mean?" The interviews, which lasted between 30 and 60 minutes, took place by telephone and were audio-taped with the nurses’ permission. An experienced secretary transcribed the interviews verbatim.

\subsection{Data Analysis}

Content analysis was carried out in a number of steps. In the first, the transcribed interview texts were read through several times in order to gain a sense of the whole. The text was then divided into meaning units and condensed. Focus was on the manifest content, i.e., what was said by the interviewees. The meaning units were critically analysed, reflected on, and coded. The codes were then compared and checked for differences and similarities, after which they were sorted into one theme and five categories [22]. The co-authors discussed and reflected upon the formulated categories in order to validate them before a final decision was made [23]. 


\subsection{Ethical Considerations}

The Regional Research Ethics Committee (99310-17) and the managers in each community granted permission for the study. Verbal and written information was provided to all participating nurses. Participation was explained as voluntary, the participants could withdraw at any time without having to provide an explanation, and confidentiality would be guaranteed.

\section{Results}

The results describe the basis on which RNs make decisions, when referring older persons from nursing homes to emergency departments. One theme comprising five categories was formulated; shared responsibility in the best interest of the older person reduces feelings of insufficiency. The theme comprises five categories: complex illnesses and a non-adapted organization; competence and responsibility; open dialogues and confidence in the "inner circle"; access to the "outer circle" counteracts insecurity and hesitation before the ED referral decision.

\subsection{Complex Illnesses and a Non-Adapted Organization}

The RNs experienced high demands on their professionalism when faced with a range of conditions such as fall injuries, acute chest pain, restlessness or aggression due to dementia, and persons facing the terminal stage of their illness. The nurses often had to deal with anxious and concerned relatives who sometimes lived far away. They emphasised that the older adults in NHs today have poorer health status than previously, which leads to more acute illness. For the nurses, this meant that when an older person became seriously ill, their work became even more difficult, as they already had to deal with an unduly high diversity in their work, in the illness symptoms among the older persons, and responsibility for too many older persons, which also implied a great deal of contact with relatives.

\subsection{Competence and Responsibility}

The RNs expressed that all staff needed more knowledge and education in order to be responsible for older persons. They reported experiences of shortcoming in medical and geriatric knowledge both in terms of themselves. The RNs described experiences of having their competence called into question by hospital staff:

"We spend hours trying to contact the relevant physicians, and sometimes when you reach a nurse or physician at the hospital you feel they are questioning you and your competence”.

\subsection{Open Dialogues and Confidence in the "Inner Circle"}

The nurses stressed that they tried to focus on the best interests of the older persons. They described that they needed to feel confident concerning the older persons' and their relatives' wishes about the nursing care as well as about their staff members' assessments. The co-workers were characterised as “the inner circle”. The nurses' expectations on "the inner circle" were various: to be sensitive to the wishes of the older persons and their relatives with regard to an ED referral and to have an open dialogue with the older person and others involved about the best course of action. Sometimes it is important to remember that individual care plans existed, including caring interventions to be used in the event of deterioration in the health status of the older person. On the other hand, to have a good working relationship with colleagues and a genuine common desire to care for older persons must be present in the team, i.e., that the colleagues possess the personal qualities and social skills necessary for working with older people:

"We can talk to each other here, which allows us good contact with relatives and staff, helping us when the situation changes and a decision has to be made”.

\subsection{Access to the "Outer Circle" Counteracts Insecurity}

The RNs described the importance of closeness to and support from the Primary Health Care Centre physicians and other colleagues. When the necessary conditions were lacking it caused the nurses' insecurity and feelings of being left alone with their decision making. These more distant health care professionals were characterised as “the outer circle”. The nurses' expectations of them were:

- the physicians’ accessibility, capacity for listening, providing advice and willingness to support them in their 
decision making;

- good work routines with Primary Health Care Centre and County Council colleagues;

- confirmation from the hospital staff with regard to the older person's health status.

"We have to make many decisions by ourselves as our physicians are so far away. I usually work at the hospital where there is always someone to ask; here you are alone and always by yourself. In fact, if I sit down and start thinking about what I'm doing and consider everything, I wonder how I dare make decisions".

\subsection{Hesitation before ED Referral Decision}

When the RNs were faced with an acute situation and hesitated to take the decision about referral to an ED, it was crucial that their colleagues knew the older person well and had competence in the geriatric field. They wanted to be certain that they could rely on their colleagues' ability to recognise changes in the health status of the older person.

They found that their colleagues promptly reported changes in health status to the nurse and were sensitive towards older persons whose health had deteriorated.

"It depends on the NH staff, what they can and are able to do. Sometimes you don't know if you can leave a person with a poor health status there".

\subsection{Comprehensive Understanding}

The findings of this study described the RNs' experiences of the situations when they make a decision in which they hesitated to refer an old person to an ED. In such cases they carefully considered the advice received from "the inner and outer circles", reflecting back and forth. When there was no response from the outer circle, e.g., when they could not contact the physician, they had to rely on their own judgment about an ED referral. The dialogues with the "inner circle" then became extremely crucial because if the nurse decided not to refer the person, she/he had to be confident that the staff members were competent enough to handle the acute and deteriorated health condition at the nursing home. This aspect took precedence over previous recommendations contained in the care plans.

\section{Discussion}

The theme "Shared responsibility in the best interest of the older person reduces feelings of insufficiency" revealed the RNs' experiences and actions as well as factors and processes influencing decision making, before the patients were referred from nursing homes to an ED. Diverse illnesses, non-adapted organizations, and complex issues had to be dealt with. Considerations about good and correct decisions were described. The RNs talked in terms of the older person's lifeworld, health and well-being as medical aspects that had to be taken into consideration, where the older person's best interests were paramount. The co-workers' judgments, competencies, and open dialogues in the "inner circle" were crucial for their confidence concerning ED referral decisions. Hesitation was expressed, associated with previous negative reactions from the hospital staff, which forced them to take several aspects into account. Sometimes they felt that they lacked sufficient medical knowledge and were uncertain how to appraise the acute symptoms or changes. Although not always optimal, access to the "outer circle”, physicians and hospital staff, was necessary to counteract feelings of insecurity about ED referral decisions.

Due to the aged population with multiple illnesses, referrals from nursing homes to EDs will probably continue to be common [24]. Although ED documentation and the opinions of ED staff have been examined, the other parties directly involved have not been considered, nor have the circumstances that contributed to the referral decisions, the NH staff members', the older persons' or their relatives' perspectives been illuminated [18]. The RNs expressed concerns about older persons with multiple illnesses, their vulnerability in exposed situations, and struggled to decide the best course of action in the changed circumstances - to refer or not to refer to the ED. Jablonski et al. [7] demonstrated that consensus among the parties directly involved in the referral decision is essential. However, conflicts were evident when, for example, the registered and licensed nurses or family members interpreted the patient's health status differently and also when they made different interpretations in terms of what was best for the person. In our study, discussions in the "inner circle" made the community nurse feel confident about the decision-making process. 
Our study reveals that structures and an organization supporting access to the "outer circle” must be in place. The RNs stressed the need for access to physicians who were willing to discuss problems, provide advice, and back up their decision making. Other studies have reported that ED referrals were made because staff members were unable to access a physician to examine the person, a family member insisted on and/or the older person requested a specific intervention such as an X-ray [7]. Discussion among different professional categories about the risks and benefits of referring an older person to an ED as opposed to remaining at the nursing home is necessary [7]. In our study, the nurses emphasised that a physician had to confirm the older person's health status to the hospital staff. In their survey, Gillespie et al. [24] found that both NH and ED staff agreed that communication between them was poor.

The RNs sometimes felt that their competence was questioned by the hospital staff, which led to hesitation. The RNs were of the opinion that the hospital staff neither understood nor respected the grounds for their ED referral decisions. A difference in the perception of social reality between professionals of different levels, educational backgrounds, and with different work tasks can explain some of these difficulties and reactions [25]. It can also be understood as a lack of clarity about who is responsible. In this sense the older ill person fell somewhere "in between" the different organisations and responsibility of the staff [26]. Several studies have claimed that most referrals to EDs from nursing homes are inappropriate [27] [28] as they contribute to overcrowding, longer waiting times, and consume a great deal of resources [29]. In the review by McCloskey [18], most of the ED referral literature is based on ED staff members' and primarily physicians' accounts, and not on nursing home health care personnel, which may say something about the prevailing hierarchy within the health care system. However, our results reveal that RNs and their co-workers requested more education in order to deal with the deterioration in the health status and multiple illnesses of older persons so that they could assume responsibility and reduce feelings of uncertainty.

The RNs were also afraid of making a wrong decision from a biomedical science perspective. In their considerations, this became the main ground for ED referrals; thus the lifeworld concerns of the older person received lower priority than medical concerns or uncertainty about symptoms. According to Nortvedt et al. [30], nurses in primary care mainly prioritise the biomedical discourse and concluded that this poses a serious challenge, in particular to older patients, as it undermines a holistic professional view.

Community care personnel in Sweden provide care delegated by the nurse, as far as possible, in accordance with the wishes and beliefs of the older person and her/his relatives. The National Board of Health and Welfare law [13] regulates the work of RNs while everyday care provided by other staff is regulated by the Social Service Act [31]. This act states that the NH environment should be characterized by social care and well-being rather than medical treatment. In changed or acute situations, the nurses reported that they were unable to delegate tasks if they were in doubt about the ability of their staff to meet the older person's needs. Similar reasoning about distrust is reported in other nursing home studies [15].

Feelings of burden were associated with responsibility for the older persons' present health status, risk of deterioration, and when the RNs felt that they or their staff lacked competence. Sarvimäki and Benkö [25] argue that the health care system is a hierarchical whole consisting of sub-systems and values in a continuous interplay. The structure and context of the sub-systems mirror each other, implying that the sub-systems encompass an organisational and a care culture, a care climate or atmosphere, the relationship between the care provider and patient, and a sub-system of individuals. For the nurses in the present study, the importance of a well functioning interplay between the sub-systems presented, the "inner and outer circles", is mirrored by their preference for good contacts and open dialogues. Another study concludes that is important for nurses in nursing homes to develop a deeper insight into what various social contacts can mean to the residents [32]. However, it is important in situations where decision making is difficult. It seems reasonable to assume that not only is the set of facts or circumstances surrounding the situation endowed with meaning, but also the relationships between the nurse, patient, and health care personnel staff members, because patients have the capacity to define and find strategies to solve their own problems [33]. This agrees with the result of the present study, where the nurses needed to feel confident with all who were involved: the older person, her/his relatives, and their staff. Although the nurses wanted to include everyone's views and opinions in their decision, they could not do so if they lacked confidence in their staff.

\section{Methodological Considerations}

In this article a qualitative method was used to illuminate the factors and processes preceding the nurses' referral 
of older persons from nursing homes to the ED. As this is a qualitative study, the results cannot be generalized to all older adult referrals but can be understood, transferred, and applied to similar situations and contexts [34].

The researcher had no influence on the choice of participants due to the random selection of the nurses. The number of participants is significant since, according to [34], the sample size in qualitative research should be large enough to achieve a variation of experiences yet small enough to permit deep analysis of the data. People who works together in an identified milieu tend to form patterns; they characterise the specific place and shape the problems most likely to occur [35]. The descriptive narratives in the interviews were derived from different nursing homes in an attempt to provide a sufficiently large variety of referral situations [36].

The first author conducted the narrative interviews and had no previous relationship with the interviewees, thereby avoiding any risk of being too familiar with them [37]. The interviewees were asked to provide an account of the situation when the health of the older person deteriorated, since the aim was to allow them to reflect on their experiences without interruption.

When analysing and formulating the categories, the description of the manifest content and the interpretation of the latent content were taken into consideration. These chosen methods of analyses seemed the most appropriate for answering the research questions. A co-assessment was performed to ensure the credibility of the categories [23] and the level of agreement was found to be high.

\section{Conclusions}

The result reveals that the RNs holistic perspective in the decision-making situation was challenged, as competence to meet the older person's needs in the NH context was lacking and thus preventing them from assuming responsibility [13]. Effectiveness concerns meeting the needs and overall aims of the individual in her/his specific and unique context [38]. The result reveals that in situations where needs were not met, the life-world concerns of the older person received a lower priority than medical concerns. Emphasizing one discourse, medical or lived experience over the other, is tragic for patients because of the caregivers' lack of essential knowledge to provide adapted and effective care. Furthermore, a dialogue between the biomedical perspective and the patient's lived experience is essential for care giving knowledge and imagination [39].

An eldercare organization designed to strengthen the nurses' and staff members' competence by means of education seems to be important for avoiding unnecessary referrals. It also appears essential to make guidelines and work routines more transparent and that the sub-systems give priority to good contacts and open dialogues. A referral due to lack of resources is not only wasteful but can worsen the older person's condition, decrease well-being, and cause confusion [17] [26].

\section{Conflict of Interest and Funding}

The authors have not received any funding or benefits from industry.

\section{Acknowledgements}

We are grateful to all the nurses who participated in the interviews and shared their experiences. The authors also wish to express their gratitude to the Ministry of Health and Social Affairs and the Swedish Association of Local Authorities in Gävleborg for grants.

\section{References}

[1] Bakalis, N., Bowman, G.S. and Porock, D. (2003) Decision Making in Greek and English Registered Nurses in Coronary Care Units. International Journal of Nursing Studies, 4, 749-760. http://dx.doi.org/10.1016/S0020-7489(03)00014-2

[2] Bucknall, T. and Thomas, S. (1997) Nurses’ Reflections on Problems Associated with Decision-Making in Critical Care Settings. Journal of Advanced Nursing, 25, 229-237. http://dx.doi.org/10.1046/j.1365-2648.1997.1997025229.x

[3] Austin, M.J. and Claassen, J. (2008) Implementing Evidence-Based Practice in Human Service Organizations: Preliminary Lessons from the Frontlines. Journal of Evidence-based Social Work, 5, 271-293. http://dx.doi.org/10.1300/J394v05n01_10

[4] Carter, M.W., Datti, B. and Winters, J.M. (2006) ED Visits by Older Adults for Ambulatory Care-Sensitive and Supply-Sensitive Conditions. The American Journal of Emergency Medicine, 24, 428-434.

http://dx.doi.org/10.1016/j.ajem.2005.12.012 
[5] Finn, J.C., Flicker, L., Mackenzie, E., Jacobs, I.G., Fatovich, D.M., Drummond, S., Harris, M., Holman, D.C. and Sprivulis, P. (2006) Interface between Residential Aged Care Facilities and a Teaching Hospital Emergency Department in Western Australia. The Medical Journal of Australia, 184, 432-435.

[6] Carter, L., Skinner, J. and Robinson, S. (2009) Patients from Care Homes Who Attend the Emergency Department: Could They Be Managed Differently. Emergency Medicine Journal, 26, 259-262. http://dx.doi.org/10.1136/emj.2008.060327

[7] Jablonski, R.A., Utz, S.W., Steeves, R. and Gray, D.P. (2007) Decisions about Transfer from Nursing Home to Emergency Department. Journal of Nursing Scholarship: An Official Publication of Sigma Theta Tau International Honor Society of Nursing/Sigma Theta Tau, 39, 266-272.

[8] McCloskey, R.M. (2011) A Qualitative Study on the Transfer of Residents between a Nursing Home and an Emergency Department. Journal of the American Geriatrics Society, 59, 717-724. http://dx.doi.org/10.1111/j.1532-5415.2011.03337.x

[9] Radwin, L.E. (1998) Empirically Generated Attributes of Experience in Nursing. Journal of Advanced Nursing, 27, 590-595. http://dx.doi.org/10.1046/j.1365-2648.1998.00548.x

[10] Carpenter, B.D., Van Haitsma, K., Ruckdeschel, K. and Lawton, M.P. (2000) The Psychosocial Preferences of Older Adults: A Pilot Examination of Content and Structure. The Gerontologist, 40, 335-348. http://dx.doi.org/10.1093/geront/40.3.335

[11] Luker, K.A., Austin, L., Caress, A. and Hallett, C.E. (2000) The Importance of "Knowing the Patient": Community Nurses’ Constructions of Quality in Providing Palliative Care. Journal of Advanced Nursing, 31, 775-782. http://dx.doi.org/10.1046/j.1365-2648.2000.01364.x

[12] Fagerberg, I. (2004) Registered Nurses’ Work Experiences: Personal Accounts Integrated with Professional Identity. Journal of Advanced Nursing, 46, 284-291. http://dx.doi.org/10.1111/j.1365-2648.2004.02988.x

[13] The National Board of Health and Welfare (2005) Quality Management and Patient Safety in Health Care. Ledningssystem för kvalitet och patientsäkerhet i hälsooch sjukvården. SOSFS 2005:12 (M) Socialstyrelsen, Stockholm. (In Swedish)

[14] The National Board of Health and Welfare (2001) National Board of Health Regulations on Competence Requirements for Nurses in Prescribing Medicines. Socialstyrelsens föreskrifter om kompetenskrav för sjuksköterskor vid förskrivning av läkemedel. SOSFS 2001:16 Socialstyrelsen, Stockholm. (In Swedish)

[15] Kihlgren, A.L., Fagerberg, I., Skovdahl, K. and Kihlgren, M. (2003) Referrals from Home Care to Emergency Hospital Care: Basis for Decisions. Journal of Clinical Nursing, 12, 28-36. http://dx.doi.org/10.1046/j.1365-2702.2003.00682.x

[16] Netting, F. and O’Connor, M. (2008) Recognizing the Need for Evidence-Based Macro Practices in Organizational and Community Settings. Journal of Evidence Based Social Work, 5, 473-496. http://dx.doi.org/10.1080/15433710802084219

[17] Nyström, M., Dahlberg, K. and Carlsson, G. (2003) Non-Caring Encounters at an Emergency Care Unit-A LifeWorld Hermeneutic Analysis of an Efficiency-Driven Organization. International Journal of Nursing Studies, 40, 761769. http://dx.doi.org/10.1016/S0020-7489(03)00053-1

[18] McCloskey, R.M. and van den Hoonaard, D. (2007) Nursing Home Residents in Emergency Departments: A Foucauldian Analysis. Journal of Advanced Nursing, 59, 186-194. http://dx.doi.org/10.1111/j.1365-2648.2007.04319.x

[19] Turjamaa, R., Hartkainen, S. and Pietilä, A.-M. (2013) Forgotten Resources of Older Home Care Clients: Focus Group Study in Finland. Nursing and Health Sciences, 15, 333-339. http://dx.doi.org/10.1111/nhs.12037

[20] Berland, A., Gundersen, D. and Bentsen, S.-B. (2012) Patient Safety and Falls: A Qualitative Study of Home Care Nurses in Norway. Nursing and Health Sciences, 14, 452-457. http://dx.doi.org/10.1111/j.1442-2018.2012.00701.x

[21] Kihlgren, A.L., Wimo, A. and Mamhidir, A.-G. (2013) Older Patients Referred by Community Nurses to Emergency Departments-A Descriptive Cross-Sectional Follow-Up Study in a Swedish Context. Scandinavian Journal of Caring Sciences, 28, 97-103.

[22] Graneheim, U.H. and Lundman, B. (2004) Qualitative Content Analysis in Nursing Research: Concepts, Procedures and Measures to Achieve Trustworthiness. Nurse Education Today, 24, 105-112. http://dx.doi.org/10.1016/j.nedt.2003.10.001

[23] Sandelowski, M. (1998) Writing a Good Read: Strategies for Re-Presenting Qualitative Data. Research in Nursing \& Health, 21, 375-382. http://dx.doi.org/10.1002/(SICI)1098-240X(199808)21:4<375::AID-NUR9>3.0.CO;2-C

[24] Gillespie, S.M., Gleason, L.J., Karuza, J. and Shah, M.N. (2010) Health Care Providers' Opinions on Communication between Nursing Homes and Emergency Departments. Journal of the American Medical Directors Association, 11, 204-210. http://dx.doi.org/10.1016/j.jamda.2009.09.002

[25] Sarvimaki, A. and Benko, S.S. (2001) Values and Evaluation in Health Care. Journal of Nursing Management, 9, 129137. http://dx.doi.org/10.1046/j.1365-2834.2001.00242.x 
[26] Kihlgren, A.L., Nilsson, M. and Sorlie, V. (2005) Caring for Older Patients at an Emergency Department-Emergency Nurses' Reasoning. Journal of Clinical Nursing, 14, 601-608. http://dx.doi.org/10.1111/j.1365-2702.2004.01104.X

[27] Saliba, D., Kington, R., Buchanan, J., Bell, R., Wang, M., Lee, M., Herbst, M., Lee, D., Sur, D. and Rubenstein, L. (2000) Appropriateness of the Decision to Transfer Nursing Facility Residents to the Hospital. Journal of the American Geriatrics Society, 48, 154-163.

[28] Cohen-Mansfield, J. and Lipson, S. (2002) Medical Decisions for Troubled Breathing in Nursing Home Residents. International Journal of Nursing Studies, 39, 557-561. http://dx.doi.org/10.1016/S0020-7489(01)00061-X

[29] Purdy, W. (2002) Nursing Home to Emergency Room? The Troubling Last Transfer. The Hastings Center Report, 32, 46-48. http://dx.doi.org/10.2307/3528135

[30] Nortvedt, P., Pedersen, R., Grothe, K.H., Nordhaug, M., Kirkevold, M., Slettebo, A., Brinchmann, B.S. and Andersen, B. (2008) Clinical Prioritisations of Healthcare for the Aged-Professional Roles. Journal of Medical Ethics, 34, 332 335. http://dx.doi.org/10.1136/jme.2007.020693

[31] Social Service Act (2001) The Social Service Act of Sweden.

[32] Westin, L., Öhrn, I. and Danielson, E. (2012) Residents' Experiences of Encounters with Relatives and Significant Persons: A Hermeneutic Study. Nursing and Health Sciences, 14, 495-500. http://dx.doi.org/10.1111/j.1442-2018.2012.00731.x

[33] Coleman, P.G., Carare, R.O. and Petrov, I. (2011) Spiritual Belief, Social Support, Physical Functioning and Depression among Older People in Bulgaria and Romania. Aging \& Mental Health, 15, 327-333. http://dx.doi.org/10.1080/13607863.2010.519320

[34] Sandelowski, M. (1995) Sample Size in Qualitative Research. Research in Nursing \& Health, 18, 179-183. http://dx.doi.org/10.1002/nur.4770180211

[35] Leininger, M. (1991) Transcultural Care Principles, Human Rights, and Ethical Considerations. Journal of Transcultural Nursing, 3, 21-23.

[36] Kvale, S. (1997) The Qualitative Research Interview. Den kvalitativa forskningsintervjun. Studentlitteratur, Lund. (in Swedish)

[37] Mishler, E.G. (1986) Research Interviewing: Context and Narrative. Harvard University Press, Cambridge, 53-59.

[38] Mantzoukas, S. (2007) The Evidence-Based Practice Ideologies. Nursing Philosophy: An International Journal for Healthcare Professionals, 8, 244-255. http://dx.doi.org/10.1111/j.1466-769X.2007.00321.X

[39] Sunvisson, H., Habermann, B., Weiss, S. and Benner, P. (2009) Augmenting the Cartesian Medical Discourse with an Understanding of the Person's Lifeworld, Lived Body, Life Story and Social Identity. Nursing Philosophy: An International Journal for Healthcare Professionals, 10, 241-252. http://dx.doi.org/10.1111/j.1466-769X.2009.00413.x 